\title{
Planar morphology and controlling factors of the gullies in the Yuanmou Dry-hot Valley based on field investigation
}

\author{
DENG Qingchun ${ }^{1,2}$, MIAO Fang ${ }^{1}$, ZHANG Bin ${ }^{2}$, LUO Mingliang ${ }^{2}$, LIU Hui ${ }^{2}$, LIU Xiaojiao², QIN Fachao², \\ LIU Gangcai ${ }^{3}$ \\ ${ }^{1}$ College of Geophysics, Chengdu University of Technology, Chengdu 610059, China; \\ ${ }^{2}$ School of Land and Resources, China West Normal University, Nanchong 637009, China; \\ ${ }^{3}$ Institute of Mountain Hazards and Environment, Chinese Academy of Sciences, Chengdu 610041, China
}

\begin{abstract}
The plane form of a gully can provide a basis for evaluating the gully volume and erosion rate, acting process, and evolutionary stage. For describing the planar characteristics of a permanent gully and understanding their controlling factors, this study, utilizing a total station and GPS RTK, measured the shoulder lines and channel curves of 112 gullies in six sites of the Yuanmou Dry-hot Valley and then mapped them by ArcGIS software and calculated nine parameters. The results showed that the channel lengths range from 10.88 to $249.11 \mathrm{~m}$; the widths range from 6.20 to $40.99 \mathrm{~m}$; the perimeters range from 54.11 to $541.67 \mathrm{~m}$; the gully areas range from 153.02 to $6,930.30 \mathrm{~m}^{2}$; the left-side areas range from 92.93 to $4,027.20 \mathrm{~m}^{2}$; and the right-side areas range from 63.65 to $3,539.77 \mathrm{~m}^{2}$. The slightly sinuous and straight gullies account for $73.21 \%$ of the total gullies; the quantity of the right skewed gullies is $8.93 \%$ greater than that of the left skewed ones based on the symmetry ratio; the shape ratios range from 1.12 to 1.40 and the morphology ratios from 0.038 to 1.294 ; the fractal dimension is 1.192 . Gullies in different sites have diverse planar characteristics. Except for the symmetry index, which was close to a negatively skewed distribution, all of the other parameters had the characteristic of positively skewed distribution. The gully area is related to the length and width, but the gully length has a weak correlation with the width. The evolutionary stage, topographic conditions, strata, soil properties, and piping erosion played very important roles in the gully planar morphology. This study could provide useful information for controlling gully erosion and safeguarding human habitation and engineering buildings.
\end{abstract}

Keywords: gully; plane form; morphological parameters; controlling factors; Yuanmou Dry-hot Valley

Citation: DENG Qingchun, MIAO Fang, ZHANG Bin, LUO Mingliang, LIU Hui, LIU Xiaojiao, QIN Fachao, LIU Gangcai. 2015. Planar morphology and controlling factors of the gullies in the Yuanmou Dry-hot Valley based on field investigation. Journal of Arid Land, 7(6): 778-793. doi: $10.1007 / \mathrm{s} 40333-015-0135-8$

Gully erosion is one of the most serious environmental problems in arid and semiarid regions. Severe gully erosion can not only directly destroy roads and buildings but also lead to strong land degradation (Ireland et al., 1939; Seginer, 1966). Gully morphology, including the planar, cross-sectional, and longitudinal profiles, can act as a link between past, present, and future gully erosion (Gao, 2011). The plane form of a gully can provide a basis for evaluating the gully volume and erosion rate, acting process, and evolu- tionary stage (Wijdenes et al., 1999). In addition, prediction of the geometrical shapes of gullies (e.g. length, cross-sectional profile) is very important for soil protection and water quality evaluation (Daggupati et al., 2014).

Among the planar parameters of gullies, gully length is a very common one. Within a specific area, the length of the rill, ephemeral gully or permanent gully usually tends to be concentrated within a certain range (Burkard and Kostaschuk, 1995, 1997;

*Corresponding author: ZHANG Bin (E-mail: envgeo@163.com)

Received 2015-01-07; revised 2015-03-02; accepted 2015-07-01

(C) Xinjiang Institute of Ecology and Geography, Chinese Academy of Sciences, Science Press and Springer-Verlag Berlin Heidelberg 2015 
Zhang et al., 2007; Hobbs et al., 2013) and to follow a certain statistical distribution (Cheng et al., 2007); however, there may be great differences in length among different areas (Adediji et al., 2013). The gully length is easily interpreted with aerial photos or satellite photos, and it is thus usually used as the best parameter for estimating erosion volume (Nachtergaele and Poesen, 1999; Nachtergaele et al., 2001; Capra et al., 2005; Cheng et al., 2006; Bouchnak et al., 2009; Capra et al., 2009; El Maaoui et al., 2012; Frankl et al., 2013; Hobbs et al., 2013), and becomes an important index for understanding and evaluating the severity of erosion of the rill or gully (Casalí et al., 1999; Nachtergaele et al., 2001; Cheng et al., 2006). There is usually a power law relationship between the erosion volume of a rill or a gully and the length (Capra et al., 2009); and the relationship is correlated not with the channel type but with a different scale factor that exists for these two forms of erosion (rill and ephemeral gully) (Capra et al., 2009). The width of the gully (especially in the slope) is much smaller than the length (Brooks et al., 2009). The gully width also has regional differences (Chaplot, 2013). In addition, the width of the same gully is not fixed (Poesen and Govers, 1990), and reaches its maximum value in the middle of the gully (Billi and Dramis, 2003). The width and length of the gully are log normally distributed and positively skewed (Hancock and Evans, 2010). The area and length of the gully increase with time, which can be estimated based on continuous aerial photos (Beer and Johnson, 1963; Seginer, 1966; Stocking, 1980). The sinuosity can be used to divide the types of gullies (Gales et al., 2013) and it is a key index for the effect of liquid water on the gully erosion on Mars (Mangold et al., 2010). These sinuous gullies are mainly distributed on slopes with gradients of $10^{\circ}-20^{\circ}$ (Hobbs et al., 2013). Because the cross-sectional area and volume of gullies cannot be easily obtained based on remote sensing images (Nachtergaele and Poesen, 1999), quantitative relationships among the volume, cross-sectional area, and gully length are very important (Kompani-Zare et al., 2011).

During the period of gully initiation, the morphological characteristics of the gully length, depth, width, area, and volume are far from being stable (Sidorchuk,
1999). Rates of increase of the length and area of a single gully change with time (Burkard and Kostaschuk, 1995; Thomas et al., 2004) and have non-linear characteristics (Graf, 1977; Rutherford et al., 1997). In most cases, the rate presents an exponential decrease with time (Thomas et al., 2004), but takes a very long time to present this trend. It must be acquired with the support of technical means such as aerial photographs (Burkard and Kostaschuk, 1995). Gully expansion is the result of synthetic actions of different factors, including the drainage basin area, indices of surface runoff and precipitation, antecedent precipitation, soil moisture, indices of piping, and so on (Beer and Johnson, 1963; Seginer, 1966; Piest et al., 1975; Stocking, 1980). Gully morphology changes with the local slope characteristics, regional environment factors, flow rate, and so on (Gales et al., 2013). The fluid discharge is determined by the continuity equation, and is also a function of the channel width, depth, and velocity (Bryson et al., 2010). For both continuous and discontinuous gullies, the relationships between the area and gradient follow the same model (Vandaele et al., 1997; Frankl et al., 2011); however, there is no statistically significant relationship between the gully width and gradient (Hancock and Evans, 2006). Based on the vegetation indices quantitatively acquired by remote sensing, there is also no significant relationship between the gully width and length (Hancock and Evans, 2010). Positive interference by humans (such as soil and water conservation measures for improving the soil shear strength) will reduce the lengths of the rill and the gully (Knapen and Poesen, 2010).

Great progress has been made regarding the basic categories of gully morphology. However, there are still some deficiencies: a) rich studies of cross-sections, but fewer of the planar and longitudinal profiles of gullies; b) the lack of geometry parameters, as the existing parameters cannot characterize the plane form in detail; c) less researches on the morphology of permanent gullies compared with rill and ephemeral gullies; d) plentiful information on the morphology of the gully head, but little on the whole gully; e) fewer models for quantitatively predicting sediment yields of gully erosion based on the effect of the mechanism of the environmental conditions on the gully length or area change (Seginer, 
1966; Burkard and Kostaschuk, 1995; Vandekerckhove et al., 2000; Bouchnak et al., 2009); and f) the absence of systematic study of factors controlling the plane form of gullies. In the Yuanmou Dry-hot Valley of Yunnan province, Southwest China, which has a dry and hot climate with distinct dry and wet seasons, loose soil layers, soil mass with developed vertical joints (Fang et al., 2011), vegetation degradation, and inappropriate land use (Fan et al., 2004), the gully erosion is intensified (Liu et al., 1996). The objectives of this study are: a) to establish systematic parameters to characterize the planar characteristics of permanent gullies; and b) to understand the effects of the main controlling factors on the gully plane form.

\section{Materials and methods}

\subsection{Study area}

The Yuanmou Dry-hot Valley is located in the north of the Yunnan Plateau, Southwest China, downstream of the Longchuanjiang River (a first-order tributary of the Jinshajiang River), and between latitudes $25^{\circ} 23^{\prime}-26^{\circ} 06^{\prime} \mathrm{N}$ and longitudes $101^{\circ} 35^{\prime}-102^{\circ} 06^{\prime} \mathrm{E}$ (Fig. 1).

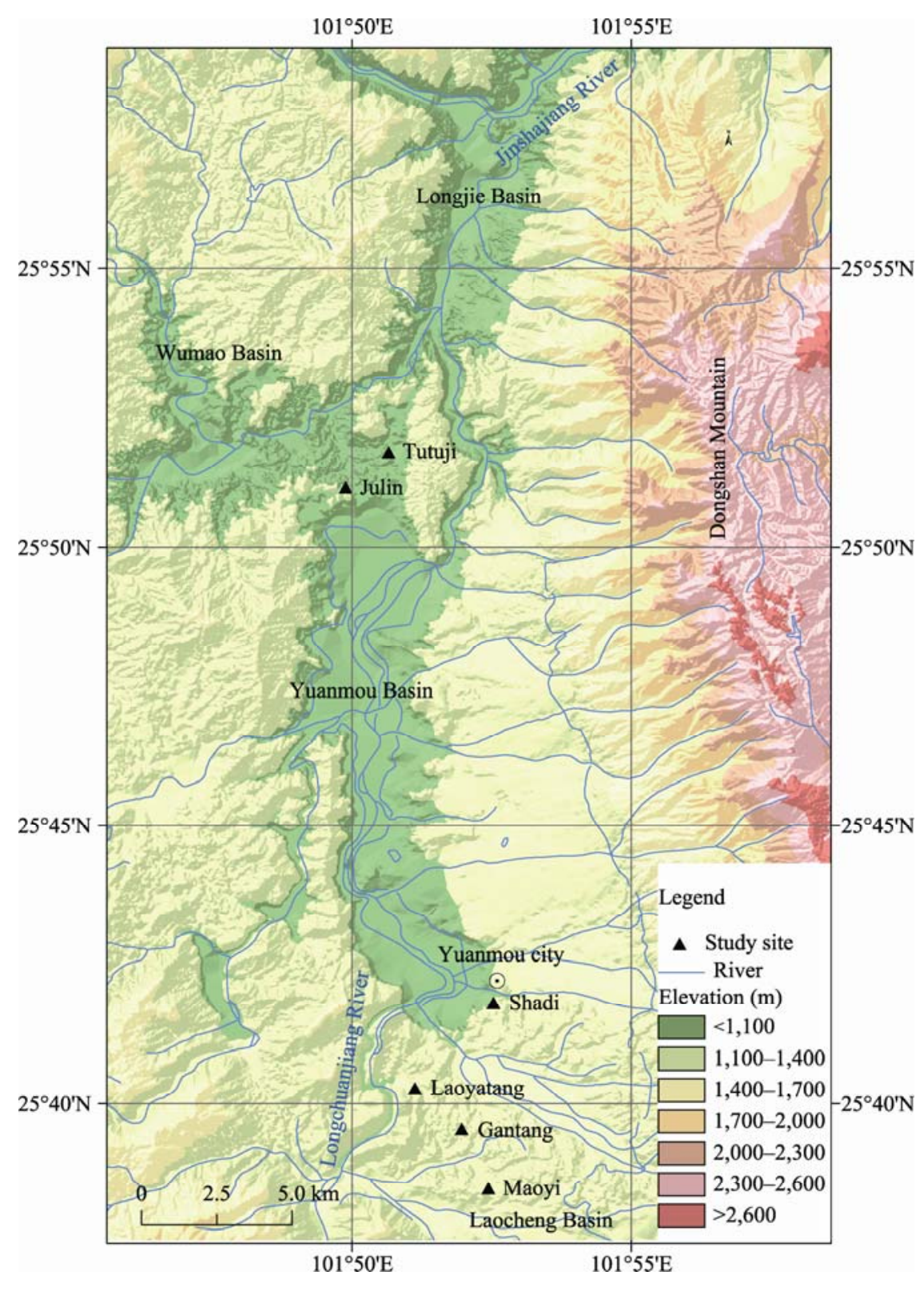

Fig. 1 The study area 
The valley, with an altitude of 980 to $1,600 \mathrm{~m}$, is cut through by the Longchuanjiang River from south to north. Eastwards is Dongshan Mountain, whose altitude is $1,000-1,200 \mathrm{~m}$ higher than the basin. The west of the valley is dominated by hills with round tops, whose altitudes are $1,300-1,500 \mathrm{~m}$. The valley is characterized by a hot weather with distinct wet and dry seasons. The annual mean temperature is $21.9^{\circ} \mathrm{C}$, with the coldest month being December (monthly mean: $14.9^{\circ} \mathrm{C}$ ) and the hottest, May (monthly mean: $27.1^{\circ} \mathrm{C}$ ). The average annual precipitation is 613.8 $\mathrm{mm}$, of which over $90 \%$ is contributed by the rainy season (May to October); sometimes the maximum daily rainfall is over $100 \mathrm{~mm}$. The annual average relative humidity is $53 \%$. Vegetation types below an altitude of 1,600 m are mainly shrub savanna, most of which includes grasses (over 90\%) in addition to a few scattered shrubs (Ji et al., 2003). The valley features dry red soil and vertisol, and has experienced serious water and soil loss owing to specific environmental conditions and human activities. The land surface is extremely damaged by gully erosion as a result of loose soils and well-developed vertical joints (Fang et al., 2011).

\subsection{Planar morphological parameters of gullies}

The planar morphological parameters of a gully can be divided into two types, namely the dimensional and the proportional parameters. The former parameters include the length, width, area, and perimeter of the gully. The latter ones include the coefficient of sinuosity, symmetry ratio, morphology ratio, shape ratio, and fractal dimension.

\subsubsection{Gully length}

The gully length includes the channel length $(L c)$ and straight length $(L s)$. Channel length is defined as the length of the gully from head to mouth along the stream channel, while the straight length is defined as the linear distance from the gully head to its mouth. For the same area, if the gully is much longer, there will be a larger drainage area and the gully will have experienced a much longer erosion process. At a given time, the length of each gully is fixed.

\subsubsection{Gully width}

The top width at any cross-section of the gully is called the gully width. A gully has many cross-sections, and thus there is more than one gully width. From the gully head to the mouth, the gully widths at $1 / 4,1 / 2$, and $3 / 4$ of the way along the gully are marked as $W_{1 / 4}, W_{1 / 2}$ (also called middle width, $W h$ ), and $W_{3 / 4}$, respectively. The value obtained by dividing erosional area $(A)$ by $L C$ is called the average width (Wa) or equivalent width (El Maaoui et al., 2012). The changes of gully widths along the gully and the length-width ratios can effectively describe the plane form of the gully.

\subsubsection{Gully perimeter}

The gully perimeter $(P)$ refers to the length of the boundary line of the gully (also called shoulder line) between the gully area and the surface erosional area. For a U-shaped gully, the shoulder line is very obvious, and the length of the shoulder line is the gully perimeter; for a V-shaped gully, the perimeter is the length of a closed curve formed by the watershed line of the inter-gully area, the gully head, and the gully mouth.

\subsubsection{Erosional area}

The erosional area $(A)$ refers to the area of the closed curve zone enclosed by the shoulder line, namely the area eroded away under gully erosion. In plane form, taking the gully bottom curve as the boundary line, along the flow direction, the area between the gully thalweg and the left gully edge line and the area between the gully bottom curve and the right gully edge line are called the left area $(A l)$ and right area $(A r)$, respectively; here, $A=A l+A r$.

\subsubsection{Coefficient of sinuosity}

The coefficient of sinuosity (Cs) refers to the ratio between the gully channel length and the straight length, namely $C s=L c / L s$. If $C s$ is greater, it indicates that the gully extends more sinuously in its direction of development. If the value is closer to 1 , the gully tends to be straighter.

\subsubsection{Symmetry index}

The symmetry index ( $\mathrm{Si}$ ) is used for measuring the difference between the severity of erosion on the left and right sides and is expressed by the ratio of the difference in area between the left and right sides to the gully area: $S i=(A l-A r) /(A l+A r)$. When $S i$ is close to 0 , it means that the gully has the morphological characteristic of near-axial symmetry. 


\subsubsection{Morphology ratio}

The morphology ratio $(M r)$ is the ratio of $A$ to the square of $L c$, namely $M r=A / L c^{2}$. If the value of $M r$ is smaller, the gully will have a more obvious belt-shaped characteristic.

\subsubsection{Shape ratio}

The plane form of a gully can be taken as a patch of landscape. The shape ratio $(S r)$ is the degree of deviation in shape between the patch and a square of the same area, and can be used for measuring the complexity of the shape. The formula for calculation of the shape ratio $(S r)$ is:

$$
S r=\frac{0.25 P}{\sqrt{A}} .
$$

When $S r=1$, the gully presents a square shape.

\subsubsection{Fractal dimension}

The fractal dimension $(D)$ of the gully plane form can be used for characterizing the degree of spatial break-up and stability. The calculation formula is as follows (Dong, 1991; Cheng, 1995; Sánchez et al., 2005):

$$
\ln A(r)=\frac{2}{D} \ln P(r)+C .
$$

Where $A(r)$ represents the erosion area of the $r^{\text {th }}$ gully in a region, $P(r)$ represents the perimeter of the $r^{\text {th }}$ gully, $C$ represents the intercept, and $D$ represents the fractal dimension. Based on the straight-line equation fitted by a set of $\ln P-\ln A$ data, $D$ can be calculated as the gradient. $D$ ranges from 1.0 to 2.0. A higher value of $D$ means that the area of the gully has a greater degree of break-up and the plane form is more complex (Sánchez et al., 2005).

\subsection{Data acquisition and processing}

At six sites (Shadi, Julin, Laoyatang, Tutuji, Maoyi, and Gantang) in the Yuanmou Dry-hot Valley, 112 gullies were selected randomly and measured with GPS RTK (Trimble 5700) and a total station (Leica TCR802). For U-shaped gullies, surveying was conducted along the shoulder line. For V-shaped gullies, it was conducted along the watershed line of the inter-gully land and along the gully head and gully mouth; from the gully head to the gully mouth, it was conducted along the thalweg at the gully bottom. The distances between each two neighboring detail points were $0.5-1.0 \mathrm{~m}$, and when the density of points increased in where there were obvious topographical changes, the distances were $0.2-0.5 \mathrm{~m}$. The error of the planar coordinates of each detail point was less than $1 \mathrm{~cm}$, and the error of the elevation coordination was less than $5 \mathrm{~cm}$.

The survey points of each gully were imported into ArcGIS software and were output as the point files in shp format. The detail points of the gully shoulder line were connected as closed curves. After topological smoothing, the curve was converted into a polygon. In the attribute table, $A$ and $P$ of the gully could be calculated. In the same way, these points of the gully bottom were connected to form a broken line from the gully head to the gully mouth. After smoothing treatment, the polyline curve was generated. In the attribute list, $L c$ could be calculated. The smooth gully boundary curve and the gully bottom line were merged to form new lines and then converted to form the areal elements to obtain the areas of the left and right parts ( $\mathrm{Al}$ and $\mathrm{Ar}$ ). With the "measure" tool, it was possible to directly measure and calculate the straight distance from the gully head to the gully mouth and also to measure and calculate $W_{1 / 4}, W_{1 / 2}$, and $W_{3 / 4}$. Thus Cs, Si, Mr, Sr and Wa could be calculated. The fractal dimension $(D)$ of the group could be fitted with several sets of $P$ and $A$. The coefficient of skewness $(S k)$ and coefficient of kurtosis $(\mathrm{Ku})$ were used for characterizing the parameter distribution. Statistical analysis of these parameters was conducted in Microsoft Excel.

\section{Results}

\subsection{Dimensional characteristics}

In the Yuanmou Dry-hot Valley, gully lengths are less than $250 \mathrm{~m}$. The gullies with channel length $(L c)$ of 0-100 m account for $83.96 \%$ of the 112 gullies, and there are only four gullies whose $L c$ are more than 150 $\mathrm{m}$. The variation of straight length $(L s)$ is similar to channel length (Fig. 2).

The average widths $(W a)$ of the gullies range from 6.20 to $40.99 \mathrm{~m}$, and the widths are mainly distributed in the range of $10-30 \mathrm{~m}$, accounting for $83.04 \%$ of total gullies. The middle widths of the gullies $(\mathrm{Wh})$ range from 7.76 to $59.35 \mathrm{~m}$, and the gullies mainly 
distributed in the range of $10-30 \mathrm{~m}$ account for $72.32 \%$ of the total gullies (Fig. 3).

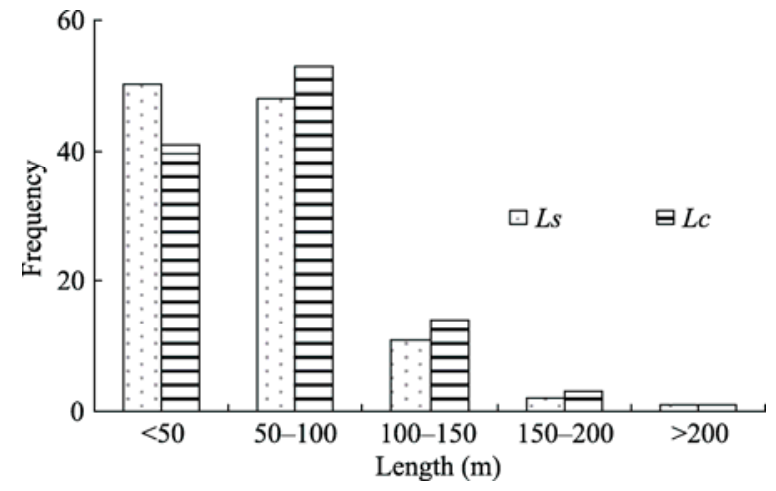

Fig. 2 Frequency distribution of gully lengths

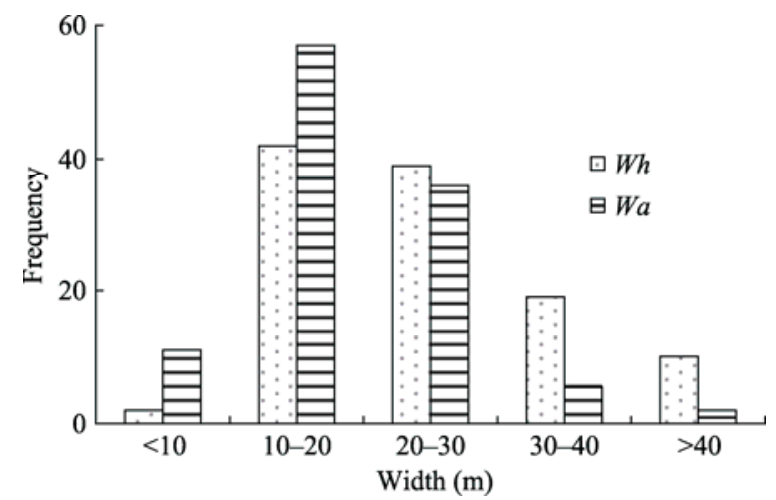

Fig. 3 Frequency distribution of gully widths

The perimeter values $(P)$ of the gullies are distributed within the range of 54.11-541.67 m. The gullies mainly distributed in the range of $100-200 \mathrm{~m}$ accounting for $54.46 \%$ of the total gullies (Fig. 4).

Erosional area (A) ranges from 153.02 to $6,930.30 \mathrm{~m}^{2}$;

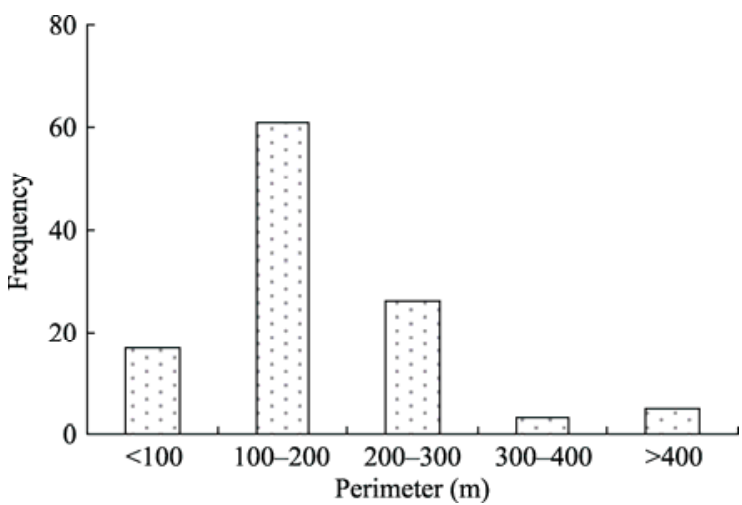

Fig. 4 Frequency distribution of gully perimeter the values are mainly distributed in the range of $500-1,500 \mathrm{~m}^{2}$, accounting for $51.79 \%$ of the total gullies (Fig. 5a). Al ranges from 92.93 to $4,027.20 \mathrm{~m}^{2}$; the gullies less than $1,000 \mathrm{~m}^{2}$ are dominant, accounting for $79.46 \%$ of the total gullies. Ar ranges from 63.65 to $3,539.77 \mathrm{~m}^{2}$, and the gullies with $\mathrm{Ar}$ less than $1,000 \mathrm{~m}^{2}$ account for $74.11 \%$ of the total gullies (Fig. $5 b$ ).
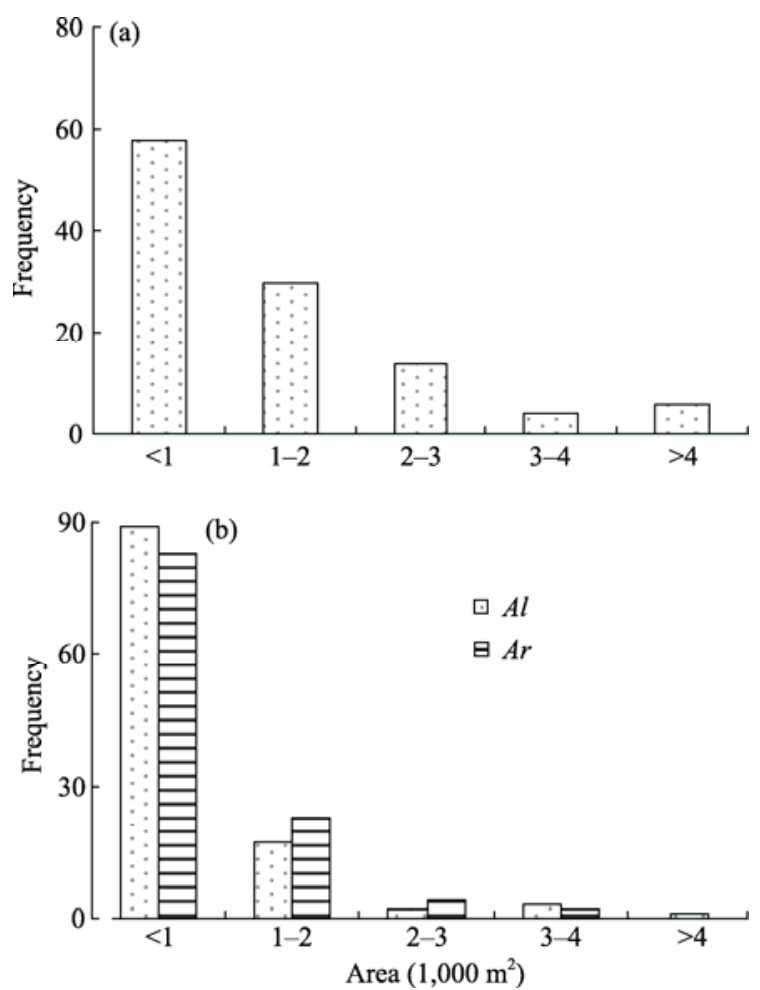

Fig. 5 Distribution of erosional area. (a) frequency distribution of erosional area; (b) frequency distribution of erosional areas of different parts.

\subsection{Proportional characteristics}

The plane form of the gullies is not always smooth and straight, although the gullies do not have a greater coefficient of sinuosity than the river. Based on the coefficient of sinuosity, there are four categories of gullies: those with Cs values less than 1.05 are called straight gullies, those with Cs values of 1.05-1.10 are called slightly sinuous gullies, those with Cs values of $1.10-1.20$ are called sinuous gullies, and those with Cs values greater than 1.20 are called extremely sinuous gullies. In the Yuanmou Dry-hot Valley, the slightly sinuous type of plane form is dominant, accounting for $39.29 \%$ of the total gullies, and the straight type accounts for $33.93 \%$. The sinuous type 
accounts for $21.43 \%$ and the extremely sinuous type accounts for only $5.36 \%$.

Taking the gully bottom line as the axis, the plane form of the gully does not always present axial symmetry. If $S i$ is a positive value, it indicates that the left-side area is larger than the right-side area, and the gully is eroded toward the right side and is the right skewed type. If $S i$ is a negative value, it indicates that the left-side area is smaller than the right-side area and the gully is eroded toward the left side and is the left skewed type. If $S i$ is between -0.1 and 0.1 , the effect of erosion toward the left or the right is not obvious, and it can be taken to be a symmetrical gully. In the Yuanmou Dry-hot Valley, Si is close to a normal distribution (Fig. 6). The extreme value of the right skewed type is 0.34 , and the extreme value of the left skewed type is -0.55 . The distribution of different skewed types in different sites is shown in Table 1. In Julin, Laoyatang, and Maoyi, the quantity of right skewed gullies is greater than that of left skewed ones, which is similar to the cross-sections (Deng et al., 2015).

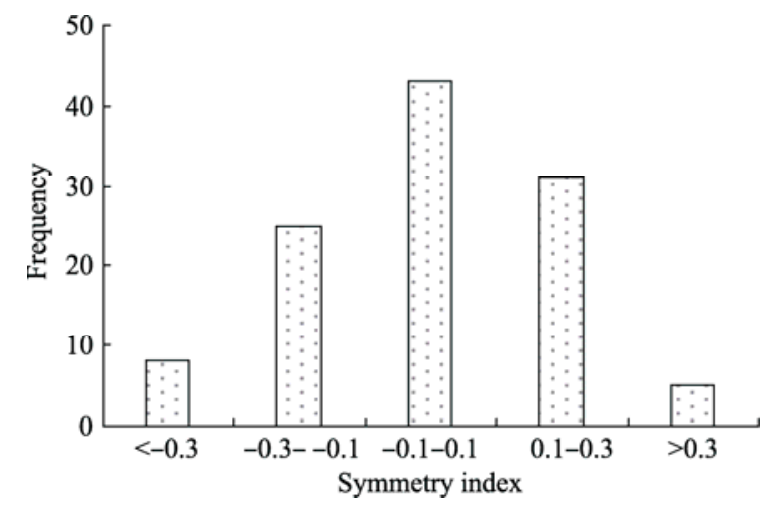

Fig. 6 Distribution of symmetry index

Table 1 Symmetry indices of the gullies in different places

\begin{tabular}{cccc}
\hline \multirow{2}{*}{ Site } & \multicolumn{3}{c}{ Number of gullies } \\
\cline { 2 - 4 } & Right-skewed & Left-skewed & Symmetrical \\
\hline Gantang & 2 & 2 & 1 \\
Julin & 27 & 17 & 12 \\
Laoyatang & 4 & 3 & 7 \\
Maoyi & 11 & 7 & 2 \\
Shadi & 1 & 5 & 2 \\
Tutuji & 3 & 4 & 2 \\
Total & 48 & 38 & 26 \\
\hline
\end{tabular}

The shape ratio (Sr) represents the difference between the plane form of the gully and a square with the same area as the gully. The minimum value of the index is 1.0. If the value is closer to 1 , it indicates that the patch shape is closer to a square. If the value is larger, the patch shape has a greater difference from a square and is more complex or flatter and longer. In the Yuanmou Dry-hot Valley, the minimum Sr is 1.12, the maximum value is 1.98 , mainly ranging from 1.2 to 1.4 and accounting for $42.86 \%$ of the total gullies (Fig. 7). Thus, the plane form of the gullies in the dry-hot valley is fairly complex.

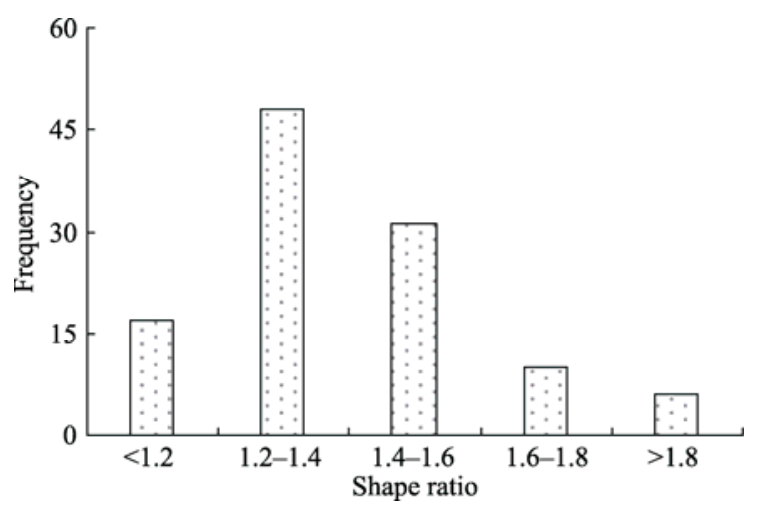

Fig. 7 Distribution of shape index

The morphology ratio $(\mathrm{Mr})$ is a parameter that describes the narrowness and length characteristics of the gully. When $M r=1.0$, the plane form is square; as $\mathrm{Mr}$ becomes smaller, the shape becomes narrower and longer. The minimum value of $\mathrm{Mr}$ is 0.038 , the maximum value is 1.294 , and the average value is 0.317 (Fig. 8). The morphology ratios are mainly distributed in the range of $0.15-0.30$, accounting for $48.21 \%$ of the total gullies; there are only three gullies with $\mathrm{Mr}$ values greater than 0.60 , and a gully has an $M r$ value of 1.294 , which is irregular and may be caused by piping erosion. When the $M r$ value is fairly small and $C s$ is larger, the gully's plane form tends to be sickle shaped.

The P-A fractal dimension $(D)$ of the gully plane is one of the effective parameters for characterizing the shape complexity. $D$ reflects the complexity of the geographical patch in a site. If the $D$ value is much larger, it indicates that the mosaic structure in this region is more complex. $D=2.0$ indicates a patch with the most complex pattern for the same area. When the value of $D$ is smaller, it shows that the mosaic struc- 
ture is simpler. The $D$ value of gullies in the dry-hot valley is 1.192 , which indicates that the mosaic structure is fairly simple as a whole (Fig. 9). With regard to the different sites, the fractal dimensions of the gullies in Maoyi and Tutuji are somewhat greater, with values of 1.316 and 1.308 , respectively. The fractal dimensions in Gantang, Julin, Laoyatang, and Shadi range from 1.1 to 1.2 (Table 2). These values conform to the complex patterns of the gullies observed in the field. Regarding the different gully types, the fractal dimensions of U-shaped and intermediate-shaped gullies are fairly small, with values of 1.073 and 1.004 , respectively. The values of $\mathrm{V}$-shaped and shallow $\mathrm{V}$-shaped gullies are 1.193 and 1.303, respectively. These four gully types represent the different periods from the active to the stable and residual stages. In the active stage, U-shaped gullies are dominant, intensive incision and headward erosion are featured, and the gully plane tends to be straight. In the stable stage, V-shaped gullies are dominant with strong lateral erosion and the plane form becomes complex. The residual stage is characterized by shallow V-shaped and lateral erosion, incision, and sedimentary interaction for a long time, so the plane form is broken up and becomes more complex, and thus the fractal dimension tends to be greater.

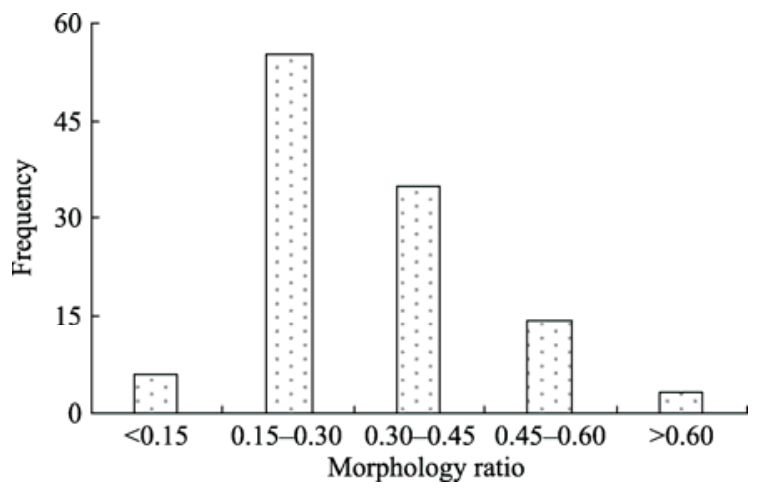

Fig. 8 Distribution of morphology ratio

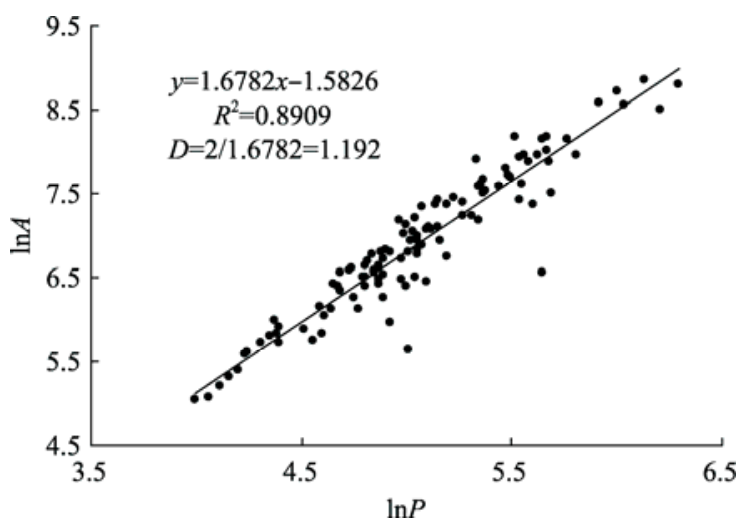

Fig. 9 A-P relationship for the permanent gullies

Table 2 Fractal dimensions of the gullies at different sites and with cross-section shapes

\begin{tabular}{|c|c|c|c|c|}
\hline \multicolumn{2}{|c|}{ Type } & Number of gullies & $R^{2}$ & Fractal dimension \\
\hline \multirow{6}{*}{ Cross-section shane } & Gantang & 5 & 0.9853 & 1.1522 \\
\hline & Julin & 56 & 0.9163 & 1.1394 \\
\hline & Laoyatang & 14 & 0.8120 & 1.1152 \\
\hline & Maoyi & 20 & 0.9413 & 1.3162 \\
\hline & Shadi & 8 & 0.9643 & 1.1614 \\
\hline & Tutuji & 9 & 0.9567 & 1.3076 \\
\hline \multirow[t]{4}{*}{ Cross-section shape } & U-shaped & 14 & 0.8589 & 1.0727 \\
\hline & Intermediate-shaped & 10 & 0.8186 & 1.0042 \\
\hline & V-shaped & 75 & 0.9531 & 1.1930 \\
\hline & Shallow V & 13 & 0.6678 & 1.3028 \\
\hline
\end{tabular}

\subsection{Statistical distributions of the parameters}

For understanding the statistical distributions of the parameters of plane form, the skewness $(S k)$ and kurtosis $(K u)$ were calculated. $S k$ is a descriptor of the shape of a probability distribution. $K u$ is a measure of the "peakedness" of the probability distribution of a real-valued variable and the heaviness of its tail.

Except for $\mathrm{Si}$ with a distribution close to normal, all of the other parameters have the characteristics of skewed distribution (Table 3); the $S k$ is positive and the value is greater, which indicates that the distribution of these parameters shows a positively skewed distribution; namely the gullies with smaller dimen- 
sions are in the majority and those with greater dimensions are in the minority. Although the $K u$ of $S i$ is negative, $K u$ values of $W a$ and $W h$ are less than 3 , which indicates that there are only small differences between the values. $P$ and $L 1$ have moderate values of $K u$, and $K u$ values of $L c, C s, A r, A, A l, M r$, and $S r$ are somewhat greater and present a leptokurtic distribution, indicating that these parameters have very great differences in value.

To some degree, these parameters can reflect the evolutionary stages of the gullies. For example, for a certain slope length, if $L c$ is shorter, it represents the young period; if $L C$ is somewhat longer, it represents the older period. A positively skewed distribution may show that more gullies are in the young or active period, and thus it can characterize the evolutionary stages of the gullies.

Table 3 Skewness and kurtosis of the gully plane morphological parameters

\begin{tabular}{cccc}
\hline Parameter & Skewness & Kurtosis & Distribution \\
\hline Si & -0.42 & -0.39 & Normal distribution \\
$W a$ & 0.79 & 0.84 & Slightly positively skewed distribution \\
$W h$ & 1.11 & 1.27 & Positively skewed distribution, flat \\
$P$ & 1.57 & 3.05 & Positively skewed distribution \\
Ls & 1.62 & 3.58 & Positively skewed distribution, leptokurtic \\
Lc & 1.68 & 4.05 & Positively skewed distribution, leptokurtic \\
$\mathrm{Cs}$ & 1.86 & 4.54 & Positively skewed distribution, leptokurtic \\
$\mathrm{Ar}$ & 2.07 & 4.91 & Positively skewed distribution \\
$\mathrm{A}$ & 2.12 & 6.48 & Positively skewed distribution, leptokurtic \\
$\mathrm{Al}$ & 2.37 & 12.91 & Positively skewed distribution, leptokurtic \\
$\mathrm{Mr}$ & 2.65 & 12.11 & Positively skewed distribution, leptokurtic \\
$\mathrm{Sr}$ & 2.80 & & Positively skewed distribution, leptokurtic \\
\hline
\end{tabular}

\subsection{Relationships among the parameters}

The correlation coefficients between $A$ and $L c$ and between $A$ and $L s$ are 0.903 and 0.905 , respectively. The correlation coefficients between $A$ and $W a$ and between $A$ and $W h$ are 0.830 and 0.819 , respectively. Although there is a strong linear correlation between $A$ and length and width, there is a more significant correlation between area and length. Figure 10a shows that the erosional area presents a linear increase, as a whole, with increasing gully length. The correlation coefficients between $L c$ and $W a$ and $W h$ are 0.1159 and 0.1892 , respectively. This indicates that $L C$ increases significantly with headward erosion of the gully. However, the trend of the increase in width is not significant. This conforms to an insignificant linear relationship between $L c$ and $W a\left(R^{2}=0.3539\right.$; Fig. $10 \mathrm{~b})$. There is a very strong correlation between $P$ and $L c$. Based on the linear fitting between $P, L C$, and $L s$, the $R^{2}$ test value of the linear relationship reaches more than 0.92 (Fig. 10c). The correlation coefficients between $\mathrm{Cs}$ and $\mathrm{Mr}$, between $\mathrm{Mr}$ and $\mathrm{Sr}$, and between $C s$ and $S r$ are $-0.232,0.094$, and -0.0442 , respectively, indicating that there is a weak or no correlation among these parameters.

\subsection{Factors controlling the plane form}

Multiple factors influence gully development and its morphology. Dominant factors vary with the evolutionary stage and gully positions. For the permanent gullies in the Yuanmou Dry-hot Valley, the plane forms are mainly controlled by factors such as lithology, vegetation, soil, topography, regional geology, and the development stage of the gully.

\subsubsection{Development stage}

In the triggering and accelerated stage of gully formation, headward erosion is dominant. The flow at the gully bottom has stronger scouring and erosional forces along the flow direction and the lateral erosion is relatively weak, and thus the gully plane form presents fast growth in length and slow development in width, the dimensional parameters of the gully are fairly small, and Cs and $\mathrm{Mr}$ are also fairly small; the value of the symmetry index is close to 0 , as most of the gullies are of symmetrical type. With further development of the gully, the gully reaches the stable 

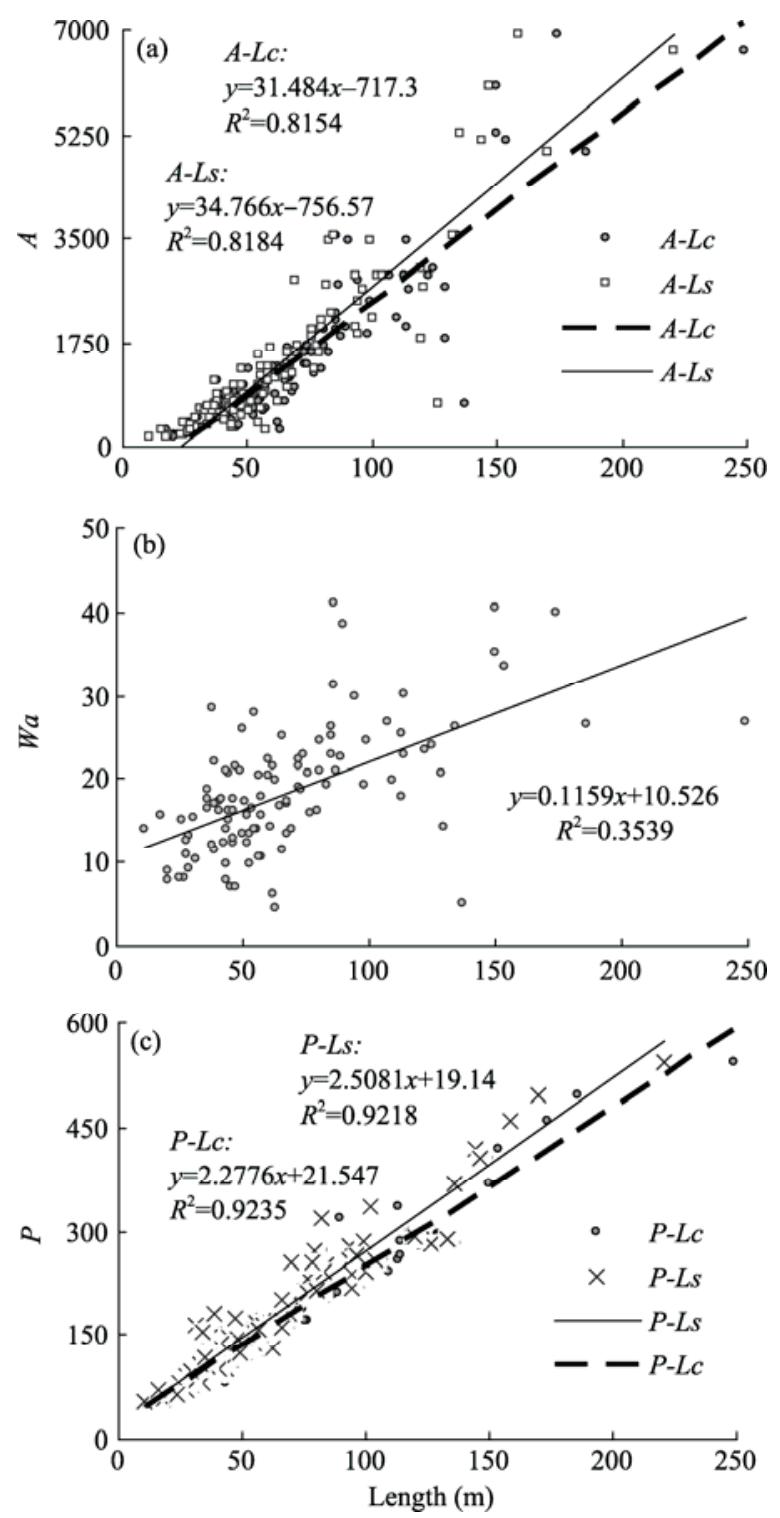

Fig. 10 Relationship between area $(A)$, average width (Wa), perimeter $(P)$ and gully length

stage, and the lateral erosion becomes stronger. Regarding the plane form, the trend of width increase becomes obvious, the length of the shoulder line increases significantly, the shape tends to be complex, $\mathrm{Cs}$ becomes great, and $\mathrm{Mr}$ increases. In the stage of denudation-planation, the gully has an irregular crisscross pattern and the land is fragmented by erosion; therefore the shape of the gully shoulder lines is too complex to clearly identify the boundary of the gully, and the gully perimeter increases significantly.

\subsubsection{Topographic conditions}

The plane form of a gully is limited by the topograph- ic conditions, mainly the slope length and gradient. The slope length can determine the maximum $L s$ in the development of the gully (namely $L s$ will not be more than the slope length), and the gradient influences the coefficient of sinuosity of the gully. The gullies in Yuanmou basin are mainly distributed in ancient proluvial or talus fans and the terraces of the valley, among which the terraces are dominant. The Yuanmou Dry-hot Valley is a long narrow valley with a south-north trend. Due to the effect of the Longchuanjiang River, which flows from south to north, the direction of development of the gullies mainly shows a nearly east-west trend. The terrace width is fairly short, and thus the lengths of the gullies developed in the region are fairly short, much smaller than those in the tableland of the Loess Plateau, whose lengths can reach several kilometers. When the gradient, especially at the gully bottom, is greater, the velocity of the water flow is faster and the scouring capability in the channel is stronger. With incision and headward erosion, the increases in gully length and depth are dominant, the channel is fairly smooth and straight, Cs and Si are smaller. When the gradient is smaller, the water flow is slower, causing lateral erosion in the channel for a long time, and the gully width increases so that $A, S i$ and Cs increase (Fig. 11). In the western hills and eastern mountainous area, due to the uplift movement of neo-tectonics, the gradient is large and the gully plane mainly tends to be straight. In the middle part lies the river terrace of Longchuanjiang River or the ancient lake basin, and the gully plane form is more sinuous there due to the gentle topographic relief.

\subsubsection{Strata}

The strata of Yuanmou Formation are distributed extensively in the basin and consist of four sections and 28 layers with a total thickness of $695.4 \mathrm{~m}$. From the upper to the lower layers (Qian and Zhou, 1991), there are deposits of fluvial facies, limnetic facies, or fluvial interbedded with limnetic facies. The lithology includes the gravel layer, silty sand layer, sub-clay layer, and clay layer interbedded with a gravel layer (Cai et al., 2001) .These sand and clay layers have great effects on the mechanical composition of the soil, and as a result the soil has high porosity and loose texture and the lithology is loose and can be easily 

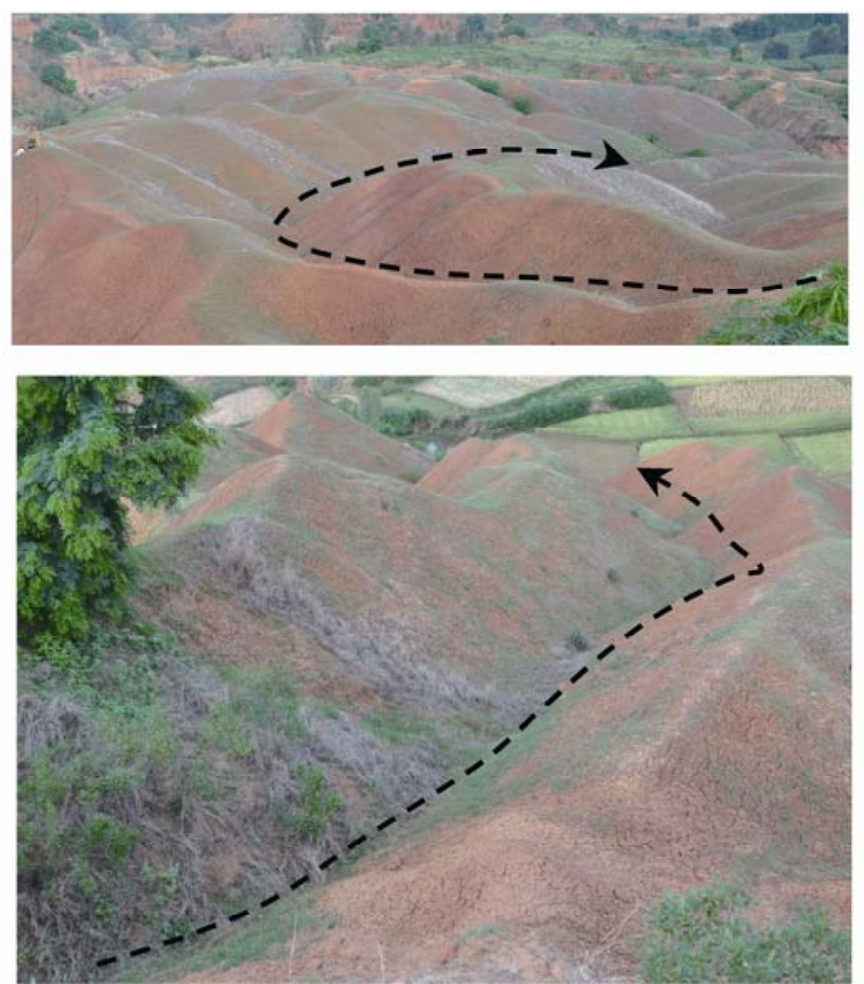

(a) The difference in height between the gully head and mouth is $16.41 \mathrm{~m}, L s$ is $93.40 \mathrm{~m}, L c$ is $122.14 \mathrm{~m}$, the gradient of the slope from the gully head to the gully mouth is $9.9^{\circ}$, and $C s$ is 1.308 .

(b) The difference in height between the gully head and mouth is $43.89 \mathrm{~m}, L s$ is $120.13 \mathrm{~m}, L c$ is $129.39 \mathrm{~m}$, the gradient of the slope from the gully head to gully mouth is $20.1^{\circ}$, and $C s$ is 1.077 .

Fig. 11 Effect of the slope on Cs at the site of Tutuji (the arrow indicates the gully mouth)

eroded, which helps to increase the length and width of the gullies. The surface weathered crust has important effects on the gully morphology (Fig. 12). The weathered crust developing in the gullies area of the dry-hot valley is mainly red iron weathered crust of the Middle Pleistocene with a thickness of $0.5-1.0 \mathrm{~m}$. The topographic relief of the weathered crust is the upper part of the gentle hills or higher terrace. When the earth's crust lifted up, the river became incised, the gullies developed, and the earth walls and earth pillars formed because the hard weathered crust provided protection for the soil layer below. The soil layer is not being washed off by the water flow from the top and will not collapse for a very long time (Qian and Zhou, 1991), and thus the existence of the weathered crust limits the increase in width during development of the gully.

\subsubsection{Soil properties}

The physical properties of the surface soil have important effects on increasing the infiltration rate of the soil and reducing the slope runoff, and, can further affect the gully morphology. In the Yuanmou Dry-hot Valley, vertisol and dry red soil have generally devel-

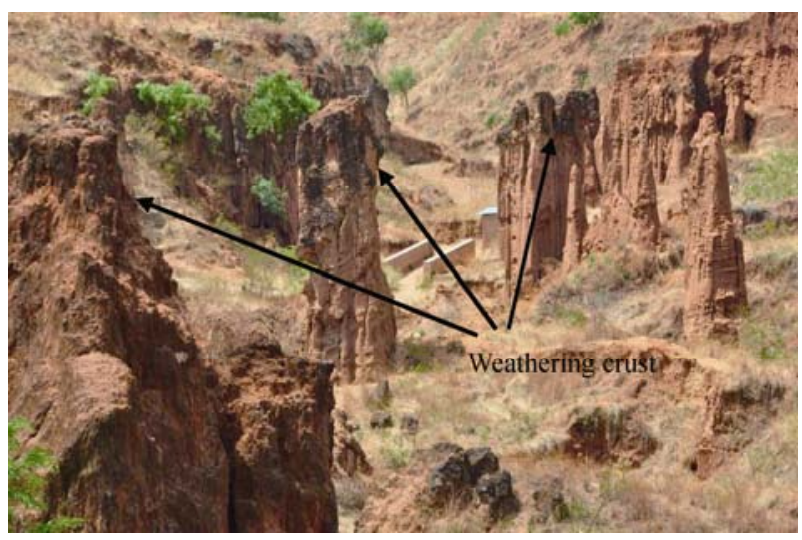

Fig. 12 Protective effect of the weathered crust for the lower soil mass

oped. Due to the homogeneity of the vertisol profile, the erodibility at each point of the profile is roughly the same; namely, it can be eroded at the same rate, and a smooth and straight ridge line is formed. Due to the heterogeneity of the profile of the dry red soil, especially the top layer covered by the weathered crust, which has very strong erosion resistance (very common in the area of dry red soil), downward erosion of the gully is limited. With stronger erosion resistance 
in the top part, and as a result of piping erosion and collapse of the gully wall, the gully shoulder line shows a high degree of zigzagging, the gully perimeter increases, the plane form becomes complex, and the shape ratio of the gully increases. The gullies in the area of dry red soil have vertical gully walls because the vertical cracks and joints are very well developed. Soil cavities are formed by lateral erosion at the gully bottom and scouring caves are formed by

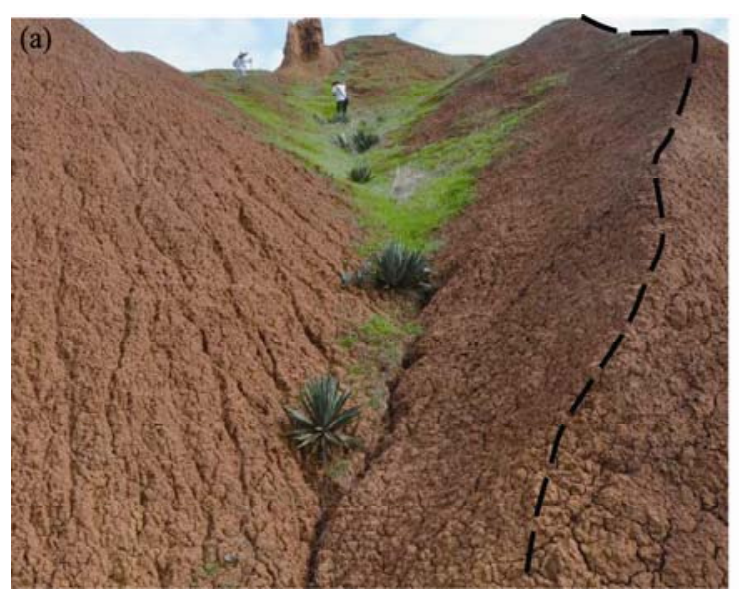

scouring erosion in the gully wall, making the soil mass in the top layer collapse due to the action of gravity, and thus the saw-toothed gully shoulder line is formed and the perimeter of the gully increases significantly. At Tutuji, where vertisol is dominant, the ratio between $P$ and $L s$ ranges from 2.37 to 2.97 ; at Julin, which has dry red soil, the ratio ranges from 2.59 to 4.68 and most of the ratio values are above 3.0 (Fig. 13).

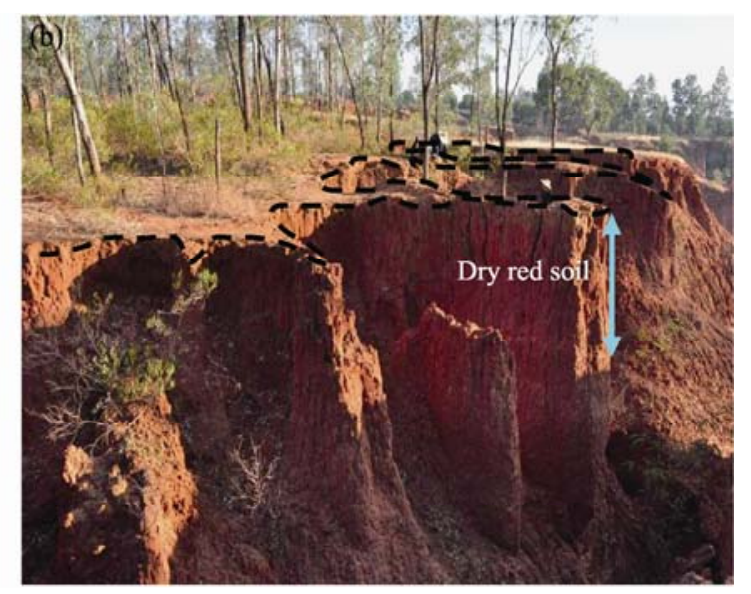

Fig. 13 Shape of shoulder line in areas of different soil types. The dotted line represents the shoulder line. (a) shoulder line in the vertisol area (Tutuji); (b) shoulder line in the dry red soil area (Shadi).

\subsubsection{Piping erosion}

Landforms caused by piping erosion are fairly well developed in the dry-hot valley and have many types and a strong influence on the gully process and morphology (Deng et al., 2014). Changes of plane form caused by piping erosion are typical in the dry-hot valley. At two disc-shaped caves formed at the gully bottom in Tutuji, the sediment is eroded and transported through an underground pipe, the profile across the cave obviously expands, and the gully perimeter and width at the position are increased (Fig. 14a). With development of the vertical hole, the gully wall collapses, the shape of the shoulder line changes clearly, the length of shoulder line increases significantly (at Shadi), and there is a sudden change during the evolutionary process (Fig. 14b). A washing hole is a semicircle-like concave shape at the gully wall. During the drainage of the slope current, a small portion of water flows along the precipitous cliff in a lamellar shape (Fig. 14c). With the scouring and licking erosion at the positions where the erosional resistance is fairly weak, the washing hole is formed. The washing hole develops in the transverse direction, and the scoured space presents a typical skirt and has a fairly large hanging surface. A washing hole is a common landform type of piping erosion at the gully head in the area of dry red soil. Collapse of a washing hole is a means of gully headward erosion. The washing hole developing at the soil cliff is the reason for the collapse and retreat of the vertical wall. Formation and subduction of the washing hole increase the length of the shoulder line at the gully head, the coefficient of sinuosity, and the planar complexity.

\section{Discussion}

The gully length, width, and area are common dimensional parameters. Gully length is an important index for evaluating the erosion volume and rate; gully width is a parameter for linking the plane and cross-section of the gully, and the area can reflect the severity of soil erosion. Thus, these three common parameters have very great significance with regard to 

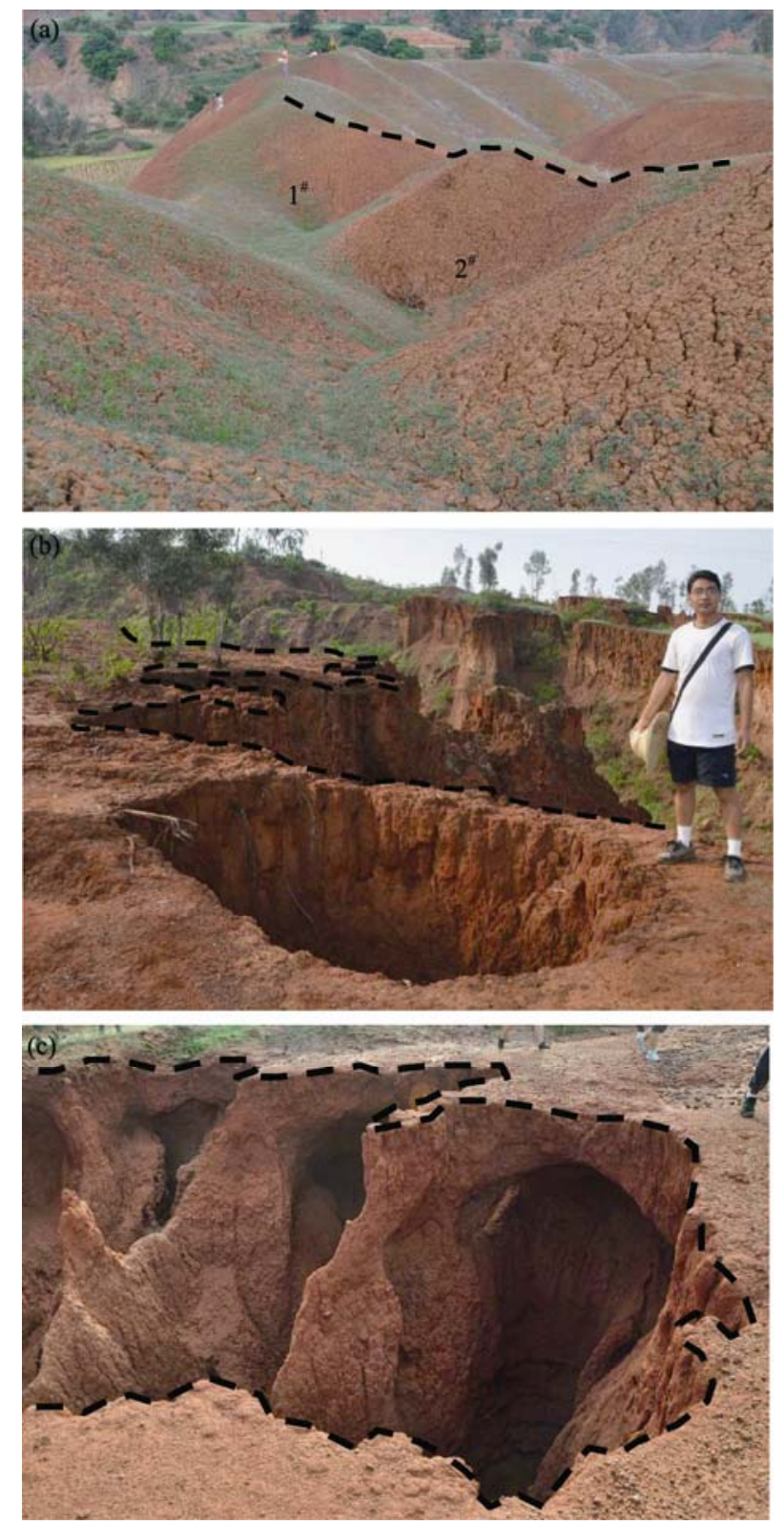

Fig. 14 Effect of piping erosion on the gully plane form. (a) dish-shaped cave; (b) vertical hole; (c) washing hole.

erosional geomorphology. However, the gully perimeter has not been considered. The gully perimeter can also be called the length of the boundary or shoulder line and can reflect the complexity of the gully plane form. For a given area, a gully with a greater perimeter will have more sinuous boundaries, so the coefficient of sinuosity can also describe the gully plane form and its complexity together with the proportional parameters. In comparison to V-shaped, U-shaped, triangular, and rectangular gully types based on the morphology of the gully cross-section (Heede, 1970;
Rustomji, 2006; Gabet and Bookter, 2008), there is less literature on the gully types based on the gully plane form except for works on the coefficient of sinuosity of straight and sinuous gullies. In this paper, the sinuous gullies have been subdivided into the slightly sinuous, sinuous, and extremely sinuous types. The classification method is similar to classification of the river pattern in fluvial geomorphology. However, based on the geological background, hydrodynamic force, and complex boundary conditions in a wide region, the river morphology is so complex that the coefficient of sinuosity is always high. Based on the symmetry index, the gullies can also be divided into left skewed, symmetric, and right skewed types (Zhang et al., 2008). Further exploration is still necessary with regard to classifying the gully morphology based on the shape ratio, morphology ratio, and fractal dimension, or based on multiple parameters from comprehensive and quantitative perspectives. For these types, from the perspective of morphology, it is necessary to consider whether or not they can reflect the evolutionary stages and formation mechanism of the gully in order to strengthen the value of morphological research. In addition, the relationships and coupling mechanisms among the plane form, cross-section, longitudinal profile morphology, gully process, and formation mechanism are still key fields of future gully geomorphology studies.

The dimensional parameters of the plane form of the gullies in the Yuanmou Dry-hot Valley have a large range of variation, as the differences between the maximum and minimum values are greater than an order of magnitude, and the proportional parameters also have great differences. This indicates that there are great differences of the plane form of the gullies in the valley. With regard to the morphological parameters of the gully planes, except for the statistical distribution of the symmetry index, which presents a normal distribution, other parameters present a positively skewed distribution, which conforms to the research results of Hancock and Evans (2010). For the parameters with positively skewed distribution, except for the gully width, perimeter, and right-side area, other parameters have a leptokurtic distribution, indicating that the gullies with low values are in the majority, so the gullies may still be in the relatively ac- 
tive stages as a whole and will still experience very serious gully erosion in the dry-hot valley in future, and thus the task of soil and water conservation is very arduous. In the Yuanmou Dry-hot Valley, there are strong linear correlations between erosional area and channel length and gully width; in particular, the correlation between erosional area and length is more significant. There is a stronger correlation between $L c$ and $L s$, indicating that the gullies are relatively straight as a whole (Cs is lower), showing that when factors or effects such as headward erosion make the gully become longer, the complexity of the environmental conditions also continuously changes the gully direction and morphology. There is a weak correlation between gully length and average width, which indicates that the increase in length does not result in a significant change in the gully width. In addition, there is very weak or no correlation among $\mathrm{Cs}, \mathrm{Mr}$ and $\mathrm{Sr}$, which shows that parameters are mutually irreplaceable and can describe the gully plane form from different perspectives.

The river pattern is usually controlled by factors such as geological structure, strata, lithology, and topographical conditions (Zhang et al., 2008). From the river head to the estuary, these conditions change greatly, and thus the river morphology usually shows very great differences along its course. Comparatively, although there is low heterogeneity in the gully areas, the gullies have the same conditions as the formation of a river pattern but also have their own special factors. The gully plane form is caused by coupling among the geological conditions, lithology, soil, vegetation, topography, watershed morphology, and human activities. However, the regional differences of these factors result in the heteromorphy of gully morphology in different places, and the effects of different factors on the gully plane form are also different. In the Yuanmou Dry-hot Valley, the gully plane form is significantly affected by the evolutionary stage, topographical conditions, stratum, soil properties, and piping erosion, especially the last two factors. The dry red soil in local places makes the gully walls remain upright and form washing holes, resulting in a more sinuous gully edge line and more complex plane morphology. The complexity of gully plane morphology in the vertisol area is lower. Similar to the effects of piping erosion on the river and watershed morphology in the karst region, the piping erosion in the gully region may also change the gully morphology to some degree, including not only the plane form but also the cross-sectional and longitudinal profile morphology. Of course, piping erosion is also affected by unique physical and chemical properties and the profile structure of soil (Deng et al., 2014). Furthermore, the quantitative relationship between controlling factors and planar parameters, including vegetation cover and the upper drainage area, will be the focus of future work.

There are some interesting results of the study. The first is the symmetric characteristic of the plane form. Based on the symmetry index, the gullies are divided into left skewed, right skewed, and symmetric types. In the Yuanmou Dry-hot Valley, the right skewed gullies are in the majority (Deng et al., 2015). In the Northern Hemisphere, under the influence of the Coriolis force, the direction of objects' movements is right skewed, which clearly causes serious erosion of the right banks of rivers. The flow of water in the gullies has a short distance and the Coriolis force is very small, but the force still has an effect on the gully erosion; however, we cannot determine its contribution to the phenomenon of the dominance of the right skewed gully type (Deng et al., 2015). In addition, the symmetry of the gully plane form is also synthetically affected by the topography, vegetation, soil properties, and human activities. Further research is needed in the future to determine whether or not the statistical law of right skewness of the gully plane form also exists in other regions and whether or not the phenomenon will inevitably occur with the effect of the Coriolis force. The second is the effect of piping erosion on the gully plane form, which has not been discussed in the existing literature. Many types of landforms have been formed by the effect of piping erosion. The effects of different piping erosion types on the gully plane form are different to some degree, and they directly or indirectly affect the gully plane form. For example, a piping erosion pipe can make the gully length become shorter, causing the gully width to increase in the upstream part. The interaction mechanism among different piping erosion types and the gully plane form can also become a focus of gully geo- 
morphology.

\section{Conclusions}

We measured 112 permanent gullies on the basis of the field investigations in Yuanmou Dry-hot Valley using a total station and GPS RTK, and put forward nine parameters to characterize gully plane form. The gullies have relatively small sizes in length and area but complex morphology. Gullies in different sites have diverse planar characteristics. Except for the symmetry index, which was close to a negatively skewed distribution, all of the other parameters had the characteristic of positively skewed distribution. The gully area is related to the length and width, but the gully length has a weak correlation with the width. The evolutionary stage, topographic conditions, strata, soil properties, and piping erosion played very important roles in the gully planar morphology. The study is not only good for understanding the formation mechanism and evolutionary process of gullies, but also able to provide scientific references for controlling gully erosion and protecting the safety of human habitation and engineering buildings.

\section{Acknowledgements}

This work was funded by the National Natural Science Foundation of China (41101348).

\section{References}

Adediji A, Jeje L K, Ibitoye M O. 2013. Urban development and informal drainage patterns: Gully dynamics in Southwestern Nigeria. Applied Geography, 40: 90-102.

Beer C E, Johnson H P. 1963. Factors in gully growth in the deep loess area of western Iowa. Transactions of the ASAE, 6(3): 237-240.

Billi P, Dramis F. 2003. Geomorphological investigation on gully erosion in the Rift Valley and the northern highlands of Ethiopia. Catena, 50(2-4): 353-368.

Bouchnak H, Felfoul M S, Boussema M R, et al. 2009. Slope and rainfall effects on the volume of sediment yield by gully erosion in the Souar lithologic formation (Tunisia). Catena, 78(2): 170-177.

Brooks A P, Shellberg J G, Knight J, et al. 2009. Alluvial gully erosion: an example from the Mitchell fluvial megafan, Queensland, Australia. Earth Surface Processes and Landforms, 34(14): 1951-1969.

Bryson K L, Dixon J C, Sears D W G. 2010. Evaporation effects on the formation of martian gullies. Icarus, 210(1): 72-82.

Burkard M B, Kostaschuk R A. 1995. Initiation and evolution of gullies along the shoreline of Lake Huron. Geomorphology, 14(3): 211-219.

Burkard M B, Kostaschuk R A. 1997. Patterns and controls of gully growth along the shoreline of Lake Huron. Earth Surface Processes and Landforms, 22(10): 901-911.

Cai Z X, Fan J R, Liu S Z. 2001. Analysis on development characteristics and process of gully in Yuanmon Basin on Lower Reaches of Jinsha River. Scientia Geographica Sinica, 21(4): 339-343. (in Chinese)

Capra A, Mazzara L M, Scicolone B. 2005. Application of the EGEM model to predict ephemeral gully erosion in Sicily, Italy. Catena, 59(2): 133-146.

Capra A, Di Stefano C, Ferro V, et al. 2009. Similarity between morphological characteristics of rills and ephemeral gullies in Sicily, Italy. Hydrological Processes, 23(23): 3334-3341.

Casalí J, López J J, Giráldez J V. 1999. Ephemeral gully erosion in southern Navarra (Spain). Catena, 36(1-2): 65-84.

Chaplot V. 2013. Impact of terrain attributes, parent material and soil types on gully erosion. Geomorphology, 186: 1-11.

Cheng H, Wu Y Q, Zou X Y, et al. 2006. Study of ephemeral gully erosion in a small upland catchment on the Inner-Mongolian Plateau. Soil and Tillage Research, 90(1-2): 184-193.

Cheng H, Zou X Y, Wu Y Q, et al. 2007. Morphology parameters of ephemeral gully in characteristics hillslopes on the Loess Plateau of China. Soil and Tillage Research, 94(1): 4-14.

Cheng Q M. 1995. The perimeter-area fractal model and its application to geology. Mathematical Geology, 27(1): 69-82.

Daggupati P, Sheshukov A Y, Douglas-Mankin K R. 2014. Evaluating ephemeral gullies with a process-based topographic index model. Catena, 113: 177-186.

Deng Q C, Zhang B, Luo J, et al. 2014. Types and controlling factors of piping landform in Yuanmou dry-hot valley. Journal of Arid Land Resources and Environment, 28(8): 138-144. (in Chinese)

Deng Q C, Qin F C, Zhang B, et al. 2015. Characterizing the morphology of gully cross-sections based on PCA: A case of Yuanmou dry-hot valley. Geomorphology, 228: 703-713.

Dong L K. 1991. Fractal Theory and its Applications. Shenyang: Liaoning Publisher of Science and Technology. (in Chinese)

El Maaoui M A, Felfoul M S, Boussema M R, et al. 2012. Sediment yield from irregularly shaped gullies located on the Fortuna lithologic formation in semi-arid area of Tunisia. Catena, 93: 97-104.

Fan J R, Liu S Z, Zhou C B, et al. 2004. Impacts of LUCC on gully erosion in Yuanmou Basin of Jinshajiang arid-hot valley. Journal of Soil Water Conservation, 18(2): 130-132. (in Chinese)

Fang H D, Wei Y L, Liu G C, et al. 2011. Effects of soil nutrients on planted Leucaena leucocephala forest in the dry-hot Jinshajiang River valley. Arid Zone Research, 28(2): 229-234. (in Chinese)

Frankl A, Nyssen J, De Dapper M, et al. 2011. Linking long-term gully and river channel dynamics to environmental change using repeat photography (Northern Ethiopia). Geomorphology, 129(3-4): 238-251.

Frankl A, Poesen J, Scholiers N, et al. 2013. Factors controlling the morphology and volume $(V)$-length $(L)$ relations of permanent gullies in the northern Ethiopian Highlands. Earth Surface Processes and Landforms, 38(14): 1672-1684.

Gabet E J, Bookter A. 2008. A morphometric analysis of gullies scoured by post-fire progressively bulked debris flows in southwest Montana, USA. Geomorphology, 96(3-4): 298-309. 
Gales J A, Larter R D, Mitchell N C, et al. 2013. Geomorphic signature of Antarctic submarine gullies: implications for continental slope processes. Marine Geology, 337: 112-124.

Gao P. 2011. Mountain and hillslope geomorphology: Rill and gully development processes. In: Shroder J. Treatise on Geomorphology. San Diego: Elsevier Inc.

Graf W L. 1977. The rate law in fluvial geomorphology. American Journal of Science, 277(2): 178-191.

Hancock G R, Evans K G. 2006. Gully position, characteristics and geomorphic thresholds in an undisturbed catchment in northern Australia. Hydrological Processes, 20(14): 2935-2951.

Hancock G R, Evans K G. 2010. Gully, channel and hillslope erosion-an assessment for a traditionally managed catchment. Earth Surface Processes and Landforms, 35(12): 1468-1479.

Heede B H. 1970. Morphology of gullies in the Colorado Rocky Mountains. International Association of Scientific Hydrology. Bulletin, 15(2): 79-89.

Hobbs S W, Paull D J, Clarke J D A. 2013. The influence of slope morphology on gullies: Terrestrial gullies in Lake George as analogues for Mars. Planetary and Space Science, 81: 1-17.

Ireland H A, Sharpe C F S, Eargle D. 1939. Principles of gully erosion in the piedmont of South Carolina. In: Technical Bulletin No. 167374. US Department of Agriculture. Washington, DC, USA.

Ji Z H, Liu G H, Duan Y T, et al. 2003. Model of plantation restoration and ecological agriculture in fragile ecological environment in arid hot valley of Jinsha River. Journal of Soil Water Conservation, 17(5): 19-22. (in Chinese)

Knapen A, Poesen J. 2010. Soil erosion resistance effects on rill and gully initiation points and dimensions. Earth Surface Processes and Landforms, 35(2): 217-228.

Kompani-Zare M, Soufi M, Hamzehzarghani H, et al. 2011. The effect of some watershed, soil characteristics and morphometric factors on the relationship between the gully volume and length in Fars Province, Iran. Catena, 86(3): 150-159.

Liu S Z, Huang C M, Zhang J P, et al. 1996. Characteristics of land desertification and analysis of its causes in Yuanmou Region, Yunnan Province. Journal of Desert Research, 16(1): 1-8. (in Chinese)

Mangold N, Mangeney A, Migeon V, et al. 2010. Sinuous gullies on Mars: frequency, distribution, and implications for flow properties. Journal of Geophysical Research: Planets, 115(E11): E11001.

Nachtergaele J, Poesen J. 1999. Assessment of soil losses by ephemeral gully erosion using high-altitude (stereo) aerial photographs. Earth Surface Processes and Landforms, 24(8): 693-706.

Nachtergaele J, Poesen J, Steegen A, et al. 2001. The value of a physically based model versus an empirical approach in the prediction of ephemeral gully erosion for loess-derived soils. Geomorphology, 40(3-4): 237-252.

Piest R F, Bradford J M, Spomer R G. 1975. Mechanisms of erosion and sediment movement from gullies. In: Present and Prospective Technology for Predicting Sediment Yields and Sources, Agricultural Research Service Report ARS-S-40. USDA, Oxford, Mississippi.

Poesen J, Govers G. 1990. Gully erosion in the loam belt of Belgium: typology and control measures. In: Boardman J, Foster I D L, Dearing J A. Soil Erosion on Agricultural Land. Chichester, UK: John Wiley \& Sons Ltd.

Qian F, Zhou G X. 1991. Quaternary Geology and Paleoanthropology of Yuanmou Yunnan, China. Beijing: Science Press. (in Chinese)

Rustomji P. 2006. Analysis of gully dimensions and sediment texture from southeast Australia for catchment sediment budgeting. Catena, 67(2): 119-127.

Rutherford I D, Prosser I P, Davis J. 1997. Simple approaches to predicting rates and extent of gully development. In: Wang S S Y, Langendoen E J, Shields F D. Proceedings of the Conference on Management of Landscapes Disturbed by Channel Incision. Oxford, Mississippi, USA: The University of Mississippi.

Sánchez N, Alfaro E J, Pérez E. 2005. The fractal dimension of projected clouds. The Astrophysical Journal, 625(2): 849-856.

Seginer I. 1966. Gully development and sediment yield. Journal of Hydrology, 4: 236-253.

Sidorchuk A. 1999. Dynamic and static models of gully erosion. Catena, 37(3-4): 401-414.

Stocking M. 1980. Examination of the factors controlling gully growth. In: Boodt M D, Gabriels D. Assessment of Erosion. Chichester, UK: John Wiley \& Sons Ltd.

Thomas J T, Iverson N R, Burkart M R, et al. 2004. Long-term growth of a valley-bottom gully, western Iowa. Earth Surface Processes and Landforms, 29(8): 995-1009.

Vandaele K, Poesen J, Marques da Silva J R, et al. 1997. Assessment of factors controlling ephemeral gully erosion in Southern Portugal and Central Belgium using aerial photographs. Zeitschrift fur geomorphologie, 41(3): 273-287.

Vandekerckhove L, Poesen J, Oostwoud Wijdenes D, et al. 2000. Thresholds for gully initiation and sedimentation in Mediterranean Europe. Earth Surface Processes and Landforms, 25(11): $1201-1220$.

Wijdenes D J O, Poesen J, Vandekerckhove L, et al. 1999. Gully-head morphology and implications for gully development on abandoned fields in a semi-arid environment, Sierra de Gata, southeast Spain. Earth Surface Processes and Landforms, 24(7): 585-603.

Zhang B, Ai N S, Huang Z W, et al. 2008. Meanders of the Jialing River in China: Morphology and formation. Chinese Science Bulletin, 53(2): 267-281.

Zhang Y G, Wu Y Q, Lin B Y, et al. 2007. Characteristics and factors controlling the development of ephemeral gullies in cultivated catchments of black soil region, Northeast China. Soil and Tillage Research, 96(1-2): 28-41. 